\title{
Modified hybrid PWM technique for cascaded MLI and cascaded MLI application for DTC drive
}

\author{
Mahmoud Samy, Mohamed Mokhtar, Naggar Hassan Saad, Ahmed Abd El-Sattar \\ Electrical Power and Machines Department, Faculty of Engineering, Ain Shams University, Cairo, Egypt
}

\begin{abstract}
Article Info
Article history:

Received May 2, 2021

Revised Jan 26, 2022

Accepted Feb 2, 2022

\section{Keywords:}

Direct torque control H-PWM

Modulation technique

Multilevel inverter

Total harmonic distortion

ABSTRACT

Multilevel inverter is increasingly utilised for DC/AC conversion in multiple electrical power applications due to its wide capabilities, low switching losses, and reduced output harmonics. Multilevel inverter faces some problems related to complex control, and high number of components. This paper presents a modified multilevel inverter topology that needs only three DC sources and eight switches to generate thirteen voltage levels. This high number of voltage levels enhances the multilevel inverter performance significantly. Also, this paper introduces a modified modulation technique to trigger the multilevel inverter switches. This modified technique is called Hybrid pulse width modulation. The modified multilevel inverter topology accompanied by the improved modulation methodology leads to a multilevel inverter of smaller size, simpler control, and staircase sinusoidal output waveform with noticeable reduction in the harmonics content without using any harmonics filter. Furthermore, the proposed multilevel inverter topology will be utilized along with a direct torque control (DTC) induction motor drive to emphasize its characteristics by improving the motor drive performance. Correspondingly, this research runs a comprehensive set of simulations to validate the features of these topology and modulation methodology through MATLAB/Simulink environment software.
\end{abstract}

This is an open access article under the $\underline{C C B Y-S A}$ license.

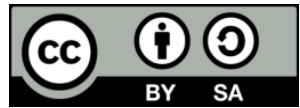

\section{Corresponding Author:}

Mahmoud Samy

Electrical Power and Machines Department, Faculty of Engineering, Ain Shams University

1 El-Sarayat St., Abbassya, 11517, Cairo, Egypt

Email: mahmoudsamy93@eng.asu.edu.eg

\section{INTRODUCTION}

Multilevel inverter (MLI) is widely used in various medium voltage and high voltage applications. MLI applications can be categorized into two main branches: motor applications and power system applications. Motor applications include motor drives to control speed and torque of motors, especially the electrical vehicle (EV) motor [1], [2]. The second branch includes various applications of power system, such as: interface between grid and renewable energy sources (solar energy, wind energy, and distributed generation (DG)), flexible AC transmission (FACT), static synchronous compensators (STATCOM), and high voltage DC (HVDC) transmission [3]-[6].

The first used inverter topology is the two-level inverter which generates two voltage levels $( \pm \mathrm{V})$. However, the performance of this inverter suffers from high total harmonic distortion (THD) and hence large filter size, high voltage rating of the switches, high switching frequency and hence further switching losses, increased voltage stress on the switches, and electro-magnetic interference (EMI) [7]. Due to the high voltage rating and voltage stress of the switches, the two-level inverter is only used with low and medium voltage applications [8]. Here comes the need for another configuration, MLI is presented to provide a DC/AC conversion with much better performance and lower THD. MLI produces staircase and smooth sinusoidal 
waveform by suitable combination of DC sources and controlled switching of power electronic devices. The first proposed MLI topology is the neutral-point clamped MLI (NPC-MLI) which adds more voltage levels to the output waveform by proper connection of DC-link capacitors, switches and clamped diodes. This configuration has many advantages over the two-level inverter, like: lower voltage rating of the switches and lower THD by increasing the voltage levels [9]. However, it suffers from some constraints, like: high quantity of components when the number of produced levels increases, and un-equal switching ratio of the switches, hence the DC-link voltage is not shared equally across the capacitors [10]. Researchers try to solve some problems of NPC-MLI by replacing the clamped diodes by auxiliary capacitors. This configuration, the Flying capacitor MLI (FC-MLI), succeeds to solve two problems of the NPC-MLI; it does not need clamped diodes, and it offers natural balancing of voltage across capacitors by redundant switching combinations for the same voltage level. Additionally, it can generate power during source outage due to the high amount of capacitors [11], [12]. But FC-MLI topology has some drawbacks: the quantity of components increases by increasing the voltage levels, and the complex control of capacitors; since its operation principle depends on charging and discharging of capacitors. An advantageous MLI topology is proposed by cascading H-Bridge cells; it is called cascaded H-bridge MLI (CHB-MLI). CHB-MLI is considered the most common MLI as it solves many problems of NPC-MLI and FC-MLI. CHB-MLI does not require clamped diodes or flying capacitors, and it requires lower number of components and simpler control of switches by offering structure modularity property. The main drawback of this configuration is the requirement of separate DC sources, so it is limited to applications of separate DC sources; renewable energy sources [13]-[15]. Porselvi and Muthu provide a comparison among NPC-MLI, FC-MLI, and CHB-MLI (classical topologies). It is found that for five-level MLI, CHB-MLI needs the lowest quantity of components, however the voltage THD is almost the same for these classical MLI topologies [16]. The major problem of using the MLI classical topologies is the increased components amount which means higher cost, more control complexity, and bigger size of MLI. So, researchers continue to contribute towards the evolution of newer topologies with lower number of components, better performance, and simpler control. In Gerardo Ceglia et al considered this major problem while proposing the T-type MLI. T-type MLI needs lower number of components if compared with the classical topologies [17]. But this reduction in components leads to some problems, like: it needs a mix of uni-directional and bi-directional switches, it operates only with symmetric sources, and switches shall have high voltage blocking capability [18]. Researchers presented another topology which solved two problems of the T-type MLI. This topology requires only uni-directional switches, and it can operate with symmetric and asymmetric DC sources. This configuration has a simpler structure and can build eleven voltage levels using three DC sources and eight switches [19].

Takahashi and Noguchi [20], proposed one of the most effective and advanced control strategies for induction motor, it is direct torque control (DTC) methodology. DTC drive principle makes use of the stator voltage and current to get estimated instantaneous values for the torque and flux. Then, an appropriate voltage vector is selected to control directly the torque and flux. This technique leads to a motor drive of superior dynamic performance without intensive calculations [21], [22]. On the other side, DTC drive suffers from high ripples in flux and torque. These ripples appear due to the dependence of DTC drive on two-level inverter. This problem can be solved by using MLI instead.

This paper presents a modified modulation technique, Hybrid pulse width modulation (H-PWM). This methodology enhances the MLI performance, and reduces the output waveform THD considerably. Additionally, this paper offers a modified configuration for a recently proposed MLI topology. This modified topology generates thirteen voltage levels by using only three DC sources and eight switches, which contributes in optimization of the MLI required components. Also, the paper presents an application for the modified MLI topology by utilizing this topology with a direct torque control (DTC) based induction motor drive. The proposed MLI configuration succeeds to improve the steady-state and dynamic performance of DTC drive at various operating conditions. In addition to decreasing the torque and flux ripples noticeably.

\section{PROPOSED MLI CONFIGURATION}

By re-constructing a recent MLI configuration, the modified MLI topology can create thirteen voltage levels instead of eleven voltage levels by involving the same components; three DC sources and eight uni-directional switches [19]. The power circuit of the proposed MLI topology is shown in Figure 1. The generated voltage levels are as follows: $\pm 3 \mathrm{E}, \pm 2.5 \mathrm{E}, \pm 2 \mathrm{E}, \pm 1.5 \mathrm{E}, \pm \mathrm{E}, \pm 0.5 \mathrm{E}$, and zero. The switches (Q, T, S1, and S2) are complementary to switches (Q', T', S1', and S2') respectively. For example, when switch (Q) is ON, switch (Q') must be OFF. The three DC sources are correlated by this ratio 1:1.5:2 to produce the thirteen voltage levels. The value of the DC source $(\mathrm{E})$ is selected depending on the application and the used switches rating. Table 1 shows the required switching combinations to obtain the thirteen voltage levels.

Int J Pow Elec \& Dri Syst, Vol. 13, No. 1, March 2022: 47-57 


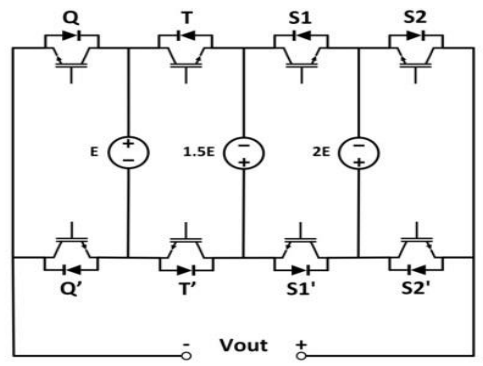

Figure 1. Proposed MLI configuration

Table 1. Proposed MLI topology switching states

\begin{tabular}{lllll}
\hline Voltage Level & $\mathrm{Q}$ & $\mathrm{T}$ & $\mathrm{S} 1$ & $\mathrm{~S} 2$ \\
\hline$+3 \mathrm{E}$ & 0 & 1 & 1 & 0 \\
$+2.5 \mathrm{E}$ & 0 & 1 & 0 & 0 \\
$+2 \mathrm{E}$ & 1 & 1 & 1 & 0 \\
$+1.5 \mathrm{E}$ & 1 & 1 & 0 & 0 \\
$+\mathrm{E}$ & 0 & 1 & 1 & 1 \\
$+0.5 \mathrm{E}$ & 0 & 0 & 1 & 0 \\
0 & 0 & 0 & 0 & 0 \\
0 & 1 & 1 & 1 & 1 \\
$-0.5 \mathrm{E}$ & 1 & 1 & 0 & 1 \\
$-\mathrm{E}$ & 1 & 0 & 0 & 0 \\
$-1.5 \mathrm{E}$ & 0 & 0 & 1 & 1 \\
$-2 \mathrm{E}$ & 0 & 0 & 0 & 1 \\
$-2.5 \mathrm{E}$ & 1 & 0 & 1 & 1 \\
$-3 \mathrm{E}$ & 1 & 0 & 0 & 1 \\
\hline
\end{tabular}

\section{PROPOSED MODULATION METHOD}

The modulation methodology for MLI is a crucial challenge as it defines directly the values of output waveform THD and MLI switching losses. Sinusoidal pulse width modulation (SPWM or PWM) and its developed forms are the most common modulation methods. PWM generates triggering pulses for inverter switches by comparing a sinusoidal reference waveform with a triangular carrier waveform. This methodology can be used with MLI by applying multiple carriers, so it is called multicarrier PWM. Multicarrier PWM is mainly classified into level-shifted PWM (LS-PWM) and phase-shifted PWM (PSPWM). For n-level MLI, LS-PWM or PS-PWM needs (n-1) carriers of the same amplitude and frequency. All carriers of LS-PWM are in phase, but carriers of PS-PWM are phase shifted. Researchers use the double Fourier series analysis to evaluate the performance of different modulation methods. A shown in (1) and (2) can express the harmonic content of output waveform of PWM, where these equations are the general form of double Fourier series analysis [23].

Equations should be placed at the center of the line and provided consecutively with equation numbers in parentheses flushed to the right margin, as in (1). The use of Microsoft Equation Editor or MathType is preferred.

$$
\begin{aligned}
& \mathrm{F}(\mathrm{t})=\frac{\mathrm{A}_{\mathrm{oo}}}{2}+\sum_{\mathrm{n}=1}^{\infty}\left\{\mathrm{A}_{\mathrm{on}} \operatorname{Cos}(\mathrm{n} \omega \mathrm{t})+\mathrm{B}_{\mathrm{on}} \operatorname{Sin}(\mathrm{n} \omega \mathrm{t})\right\}+\sum_{\mathrm{m}=1}^{\infty}\left\{\mathrm{A}_{\mathrm{mo}} \operatorname{Cos}(\mathrm{m} \omega \mathrm{t})+\mathrm{B}_{\mathrm{mo}} \operatorname{Sin}(\mathrm{m} \omega \mathrm{t})\right\} \\
& +\sum_{\mathrm{m}=1}^{\infty} \sum_{\substack{\mathrm{n}=-\infty \\
\mathrm{n} \neq 0}}^{\infty}\left\{\mathrm{A}_{\mathrm{mn}} \operatorname{Cos}(\mathrm{m} \omega \mathrm{t}+\mathrm{n} \omega \mathrm{t})+\mathrm{B}_{\mathrm{mn}} \operatorname{Sin}(\mathrm{m} \omega \mathrm{t}+\mathrm{n} \omega \mathrm{t})\right\} \\
& \mathrm{A}_{\mathrm{mn}}+\mathrm{j} \mathrm{B}_{\mathrm{mn}}=\frac{1}{2 \pi^{2}} \int_{-\pi}^{\pi} \int_{-\pi}^{\pi} \mathrm{F}(\mathrm{x}, \mathrm{y}) \mathrm{e}^{\mathrm{j}(\mathrm{mx}+\mathrm{ny})} d x d y ; \mathrm{x}=\omega \mathrm{t}, \mathrm{y}=\omega \mathrm{t}
\end{aligned}
$$

In this paper, a Hybrid PWM technique is presented, where LS-PWM and PS-PWM are merged together to get an improved modulation methodology. For n-level MLI, H-PWM requires (n-1) triangular carrier signals, where all carriers are equal in magnitude, equally level-shifted to occupy the whole sinusoidal reference signal, and each two consecutive carriers are phase-shifted by angle $\left(\theta=\frac{360^{\circ}}{n-1}\right)$ as shown in Figures 2 (a) and 2 (b). Hence, switches of MLI are controlled by the triggering signals produced by this modified methodology. The applied fundamental frequency is $50 \mathrm{~Hz}$ and the carrier frequency is $5000 \mathrm{~Hz}$.

After several iterations to select the modulation depth index value, the most effective value is 1.1 to get a reduced harmonic distortion. Where it is found that other values of modulation depth index, higher or 
lower than 1.1, give higher THD. Generally, this improved methodology grants an enhanced harmonic performance which reflects into a considerable reduction in the output waveform THD.

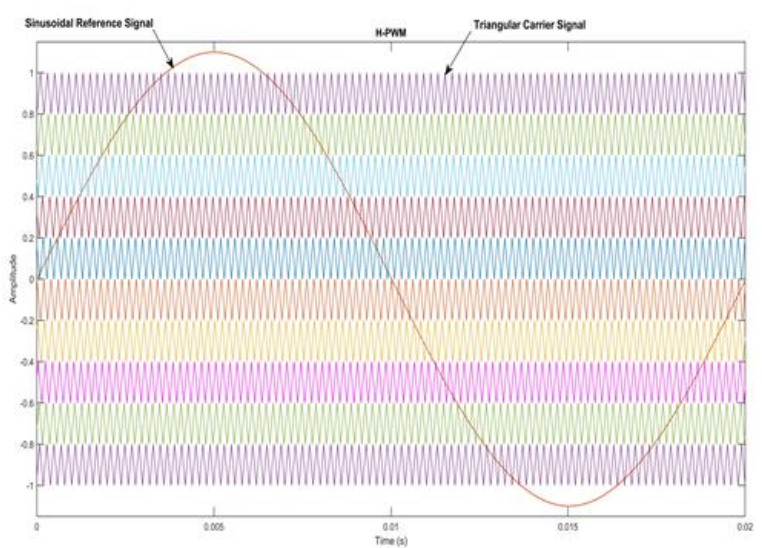

(a)

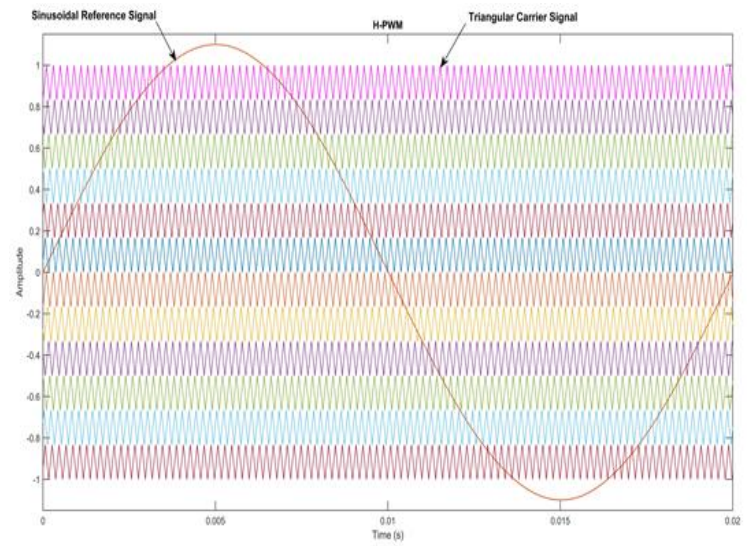

(b)

Figure 2. H-PWM technique with (a) 10 carriers for 11-level MLI and (b) 12 carriers for 13-level MLI

\section{DTC PRINCIPLE AND MLI APPLICATION}

DTC drive consists of four blocks; torque and flux estimator, torque and flux hysteresis comparators, voltage vector selection table, and inverter as shown in Figure 3. Torque and flux estimator block uses the motor stator voltage $\left(\mathrm{v}_{\mathrm{s}}\right)$ and current $\left(\mathrm{i}_{\mathrm{s}}\right)$ to estimate the instantaneous values of torque $\left(\mathrm{T}_{\mathrm{e}}\right)$, flux $\left(\emptyset_{\mathrm{s}}\right)$, and flux position $\left(\theta_{\mathrm{S}}\right)$. Motor stator voltage can be calculated from inverter switches positions and DC link voltage. At first, DTC applies Clarke Transformation to convert the stator voltage and current from $(\mathrm{a}, \mathrm{b}, \mathrm{c})$ axes to $(\alpha, \beta)$ axes. Then, DTC estimates the instantaneous values of torque, stator flux and position of stator flux (sector) using (3)-(5). The difference between the reference values (Torque*, Flux*) and measured values (Torque, Flux) gives error signals which are fed to the hysteresis comparators. Then, the torque and flux status are determined, whether inside the hysteresis band width or not. The hysteresis bands widths of torque and flux are determined based on DTC drive required performance and its capabilities. Based on the torque status, flux status and stator flux position (sector), DTC drive decides the most appropriate voltage vector from the selection table to fulfill the torque and flux reference commands. Finally, the switching (firing) pulses are injected into the inverter to trigger the switches. Consequently, DTC drive preserves the torque and stator flux inside the hysteresis band width by applying the selected voltage vector to the motor terminals.

For induction motor, the relation between stator voltage $\left(\mathrm{v}_{\mathrm{s}}\right)$, current $\left(\mathrm{i}_{\mathrm{s}}\right)$, resistance $\left(\mathrm{r}_{\mathrm{s}}\right)$ and flux $\left(\emptyset_{\mathrm{s}}\right)$ is defined in (6). Since the voltage drop across the stator resistance can be neglected. Therefore, any change in the stator voltage reflects directly into a change in the stator flux. The rotor flux $\left(\emptyset_{\mathrm{r}}\right)$ amplitude becomes constant when the amplitude of stator flux is kept within specific limits. Also, the stator voltage effect on rotor flux is negligible due to the stator and rotor leakage inductance. So, it can be concluded that the rotor flux rotates slowly, and the angle $\left(\theta_{\text {sr }}\right)$ between stator and rotor fluxes can be controlled directly by stator voltage. The developed torque $\left(\mathrm{T}_{\mathrm{e}}\right)$ of induction motor is defined in $(7)$, where $(\mathrm{P})$ is the number of poles, and $\left(\mathrm{L}_{\mathrm{s}}, \mathrm{L}_{\mathrm{r}}, \mathrm{L}_{\mathrm{m}}\right)$ are the self and mutual inductances of stator and rotor. In order to control the electromagnetic torque $\left(T_{e}\right)$, the angle $\left(\theta_{s r}\right)$ between stator and rotor fluxes needs to be regulated through applying a suitable stator voltage vector $\left(\mathrm{v}_{\mathrm{s}}\right)$. This is the basic principle of DTC which offers an improved dynamic response of induction motor [24].

$$
\begin{aligned}
& \emptyset_{\alpha s}=\int\left(v_{\alpha s}-i_{\alpha s} \cdot r_{s}\right) d t, \emptyset_{\beta s}=\int\left(v_{\beta s}-i_{\beta s} \cdot r_{s}\right) d t \\
& \mathrm{~T}_{e}=\frac{3}{2} \cdot P \cdot\left(\emptyset_{\alpha s} \cdot i_{\beta s}-\emptyset_{\beta s} \cdot i_{\alpha s}\right) \\
& \emptyset_{s}=\sqrt{\emptyset_{\alpha s}^{2}+\emptyset_{\beta s}^{2}}, \theta_{s}=\tan ^{-1} \frac{\emptyset_{\beta s}}{\emptyset_{\alpha s}}
\end{aligned}
$$




$$
\begin{aligned}
& \mathrm{v}_{\mathrm{s}}=\mathrm{i}_{\mathrm{s}} \cdot \mathrm{r}_{\mathrm{s}}+\frac{\mathrm{d} \emptyset_{\mathrm{s}}}{\mathrm{dt}} \\
& \mathrm{T}_{\mathrm{e}}=\frac{3}{2} \cdot \mathrm{P} \cdot \frac{\mathrm{L}_{\mathrm{m}}}{\mathrm{L}_{\mathrm{s}} \mathrm{L}_{\mathrm{r}}-\mathrm{L}_{\mathrm{m}}{ }^{2}} \cdot\left|\emptyset_{\mathrm{s}}\right| \cdot\left|\emptyset_{\mathrm{r}}\right| \cdot \sin \theta_{\mathrm{sr}}
\end{aligned}
$$

Typically, DTC drive utilizes a two-level inverter valid with 6 non-zero voltage vectors only. This limitation of the possible voltage vectors leads to a DTC drive of intolerable ripples in torque and flux, and increased THD content. This paper presents a solution to the voltage vectors limitation by replacing the twolevel inverter with the proposed thirteen-level MLI. The thirteen-level MLI has 126 non-zero voltage vectors as shown in Figure 4. These voltage vectors enable DTC drive to select more appropriately a voltage vector to keep flux and torque as commanded. Since the applied MLI grants a wide range of voltage vectors, hence the torque and flux ripples are reduced, and THD is limited accordingly.

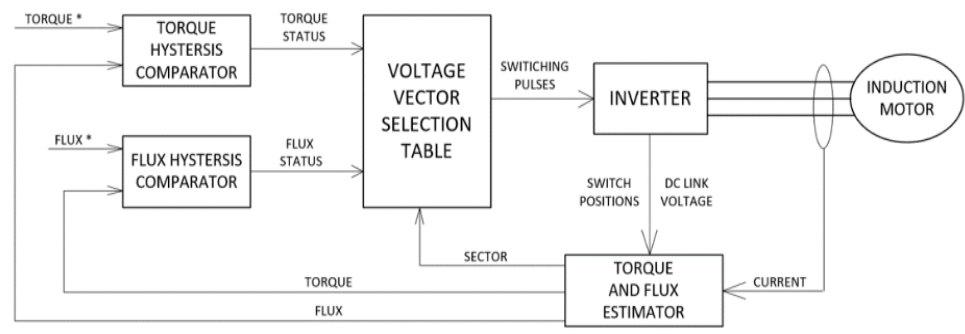

Figure 3. DTC block diagram

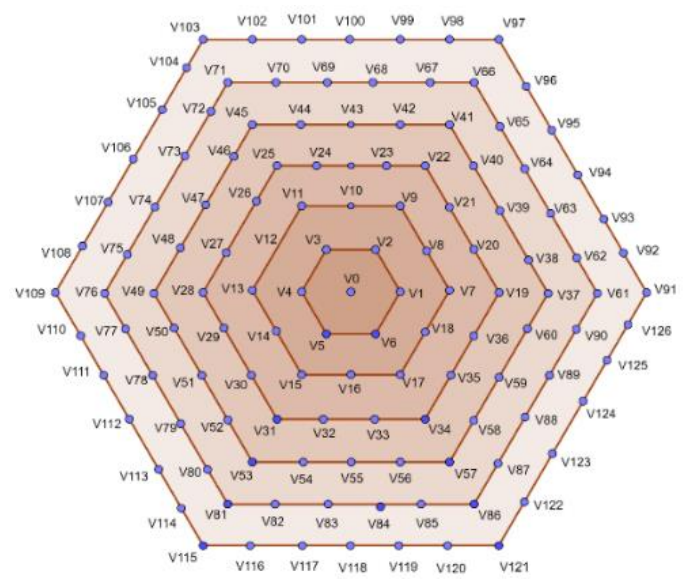

Figure 4. Space voltage vectors of 13-level MLI

\section{SIMULATION RESULTS}

This work presents detailed simulations for different case studies to verify and evaluate the performance of the modified modulation technique, the modified MLI topology, and MLI fed DTC drive. The simulations are classified into four case studies. The first case study focuses on evaluating the performance of the adjusted modulation method H-PWM. The second and third case studies focus on evaluating the performance of the proposed configuration of the thirteen-level MLI. For these three case studies, H-PWM is applied, the fundamental frequency is $50 \mathrm{~Hz}$, the carrier frequency is $5000 \mathrm{~Hz}$, and the modulation depth is 1.1; Table 2 shows the circuit parameters of each case study. By MATLAB/Simulink environment, Fast Fourier Transform (FFT) analysis is applied on each voltage or current waveform to determine the harmonic spectrum and THD magnitude. The simulations focus on THD analysis to have a clear assessment of how much the output waveform is close to the sinusoidal wave. The fourth case study introduces an assessment for the performance of DTC induction motor drive as an application for the modified MLI. DTC drive response is evaluated in steady-state and dynamic conditions, Table 3 shows the fourth case study circuit parameters. The paper depends on MATLAB/Simulink environment to construct the simulation model of DTC drive. Figure 5 (a) shows the simulation model main blocks; DTC, proposed thirteen-level MLI, and induction motor. DTC block includes torque and flux estimator, hysteresis 
comparators, and voltage vector selection table as detailed in Figure 5 (b). The voltage vector selection table contains 126 voltage vectors which are granted by the thirteen-level MLI. The proper voltage vector is selected based on torque status, flux status, and flux position (sector).

Table 2. Circuit parameters of $1^{\text {st }}, 2^{\text {nd }}$, and $3^{\text {rd }}$ case studies

\begin{tabular}{ccccc}
\hline Case Study & DC - Link voltage "E" & Inverter Topology & Modulation Technique & Load \\
\hline $1^{\text {st }}$ & $500 \mathrm{~V}$ & 11-level MLI & H-PWM & $5 \Omega, 50 \mathrm{mH}$ \\
$2^{\text {nd }}$ & $180 \mathrm{~V}$ & $13-$ level MLI & H-PWM & $34 \Omega, 15 \mathrm{mH} \& 5 \Omega, 50 \mathrm{mH}$ \\
$3^{\text {rd }}$ & $104 \mathrm{~V}$ & $13-$ level MLI & H-PWM & $3 \mathrm{Ph}$. IM - 380 V - 2.3 KW \\
\hline
\end{tabular}

Table 3. Circuit parameters of $4^{\text {th }}$ case study

\begin{tabular}{cccc}
\hline DC - Link voltage "E" & Inverter Topology & Hysteresis Band Width & Induction Motor \\
\hline $189 \mathrm{~V}$ & 13-level MLI & $2.4 \mathrm{~N} . \mathrm{m}, 0.005 \mathrm{wb}$ & $400 \mathrm{~V}, 4 \mathrm{KW}, 50 \mathrm{~Hz}, 25 \mathrm{~N} . \mathrm{m}, 1430 \mathrm{rpm}$ \\
\hline
\end{tabular}

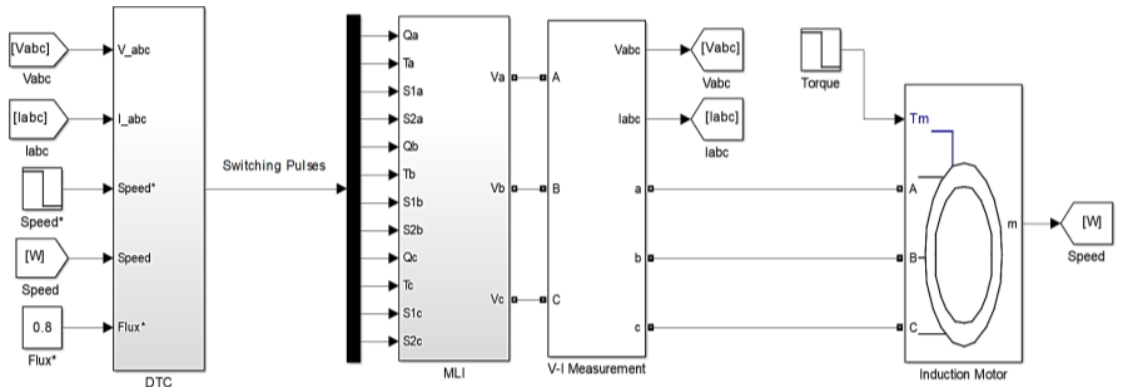

(a)

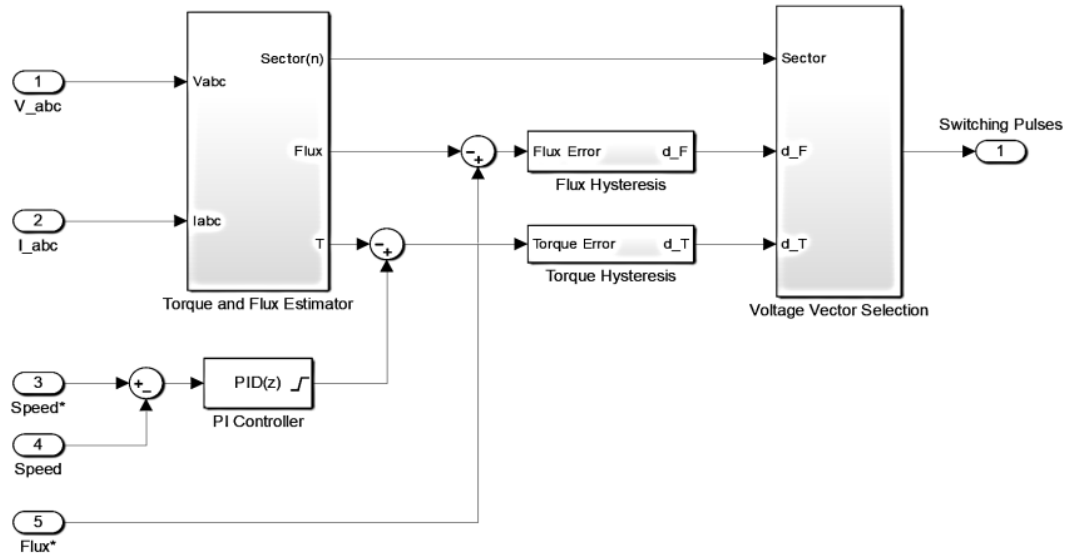

(b)

Figure 5. MATLAB/Simulink simulation model (a) Motor drive scheme and (b) DTC scheme

For the first case study (H-PWM), the circuit topology and all circuit parameters applied in [19] are kept the same, except for the modulation method. Where, H-PWM technique is applied to evaluate its performance. Figures 6 and 7 show the output phase voltage and current waveforms associated with harmonic spectrum and THD value. The results show that H-PWM succeeds to lower the harmonics content of the output waveform, where the voltage THD decreases by almost $20 \%$ (voltage THD becomes $10.03 \%$ ) if compared with the voltage THD of the PS-PWM technique. Table 4 gives a brief comparison between both of the modulation methodologies.

For the second case study, static loads are connected to the proposed MLI. Figures 8-11 show the output phase voltage and current waveforms associated with harmonic spectrum and THD value. The first load (resistive load) which has almost unity power factor includes higher current THD than the second load (resistive-inductive load) which has lower power factor $(\mathrm{P} . \mathrm{F}=0.3)$. This appears through the harmonic spectra, as all harmonic currents magnitudes after the fundamental component are reduced by adding inductive load. This is because the inductors help to suppress some orders of the harmonic currents, so the current is more sinusoidal in case of inductive load than resistive load. 

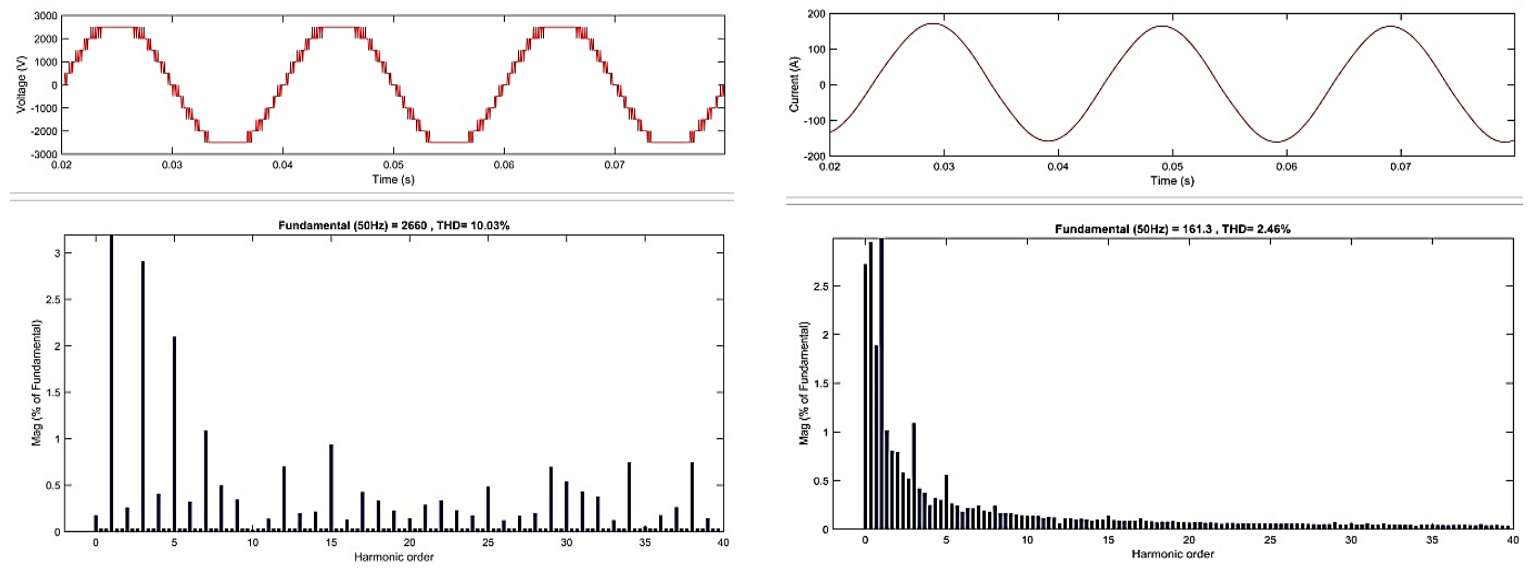

Figure 6. Voltage waveform and harmonic spectrum for $1^{\text {st }}$ case study

Figure 7. Current waveform and harmonic spectrum for $1^{\text {st }}$ case study

Table 4. Comparison between PS-PWM and H-PWM technique for 11-level MLI

\begin{tabular}{ccccc}
\hline Technique & Carrier Frequency & Modulation Depth & Fundamental Frequency & Voltage THD \\
\hline PS-PWM & $5000 \mathrm{~Hz}$ & 0.95 & $50 \mathrm{~Hz}$ & $12.48 \%$ \\
H-PWM & $5000 \mathrm{~Hz}$ & 1.1 & $50 \mathrm{~Hz}$ & $10.03 \%$
\end{tabular}
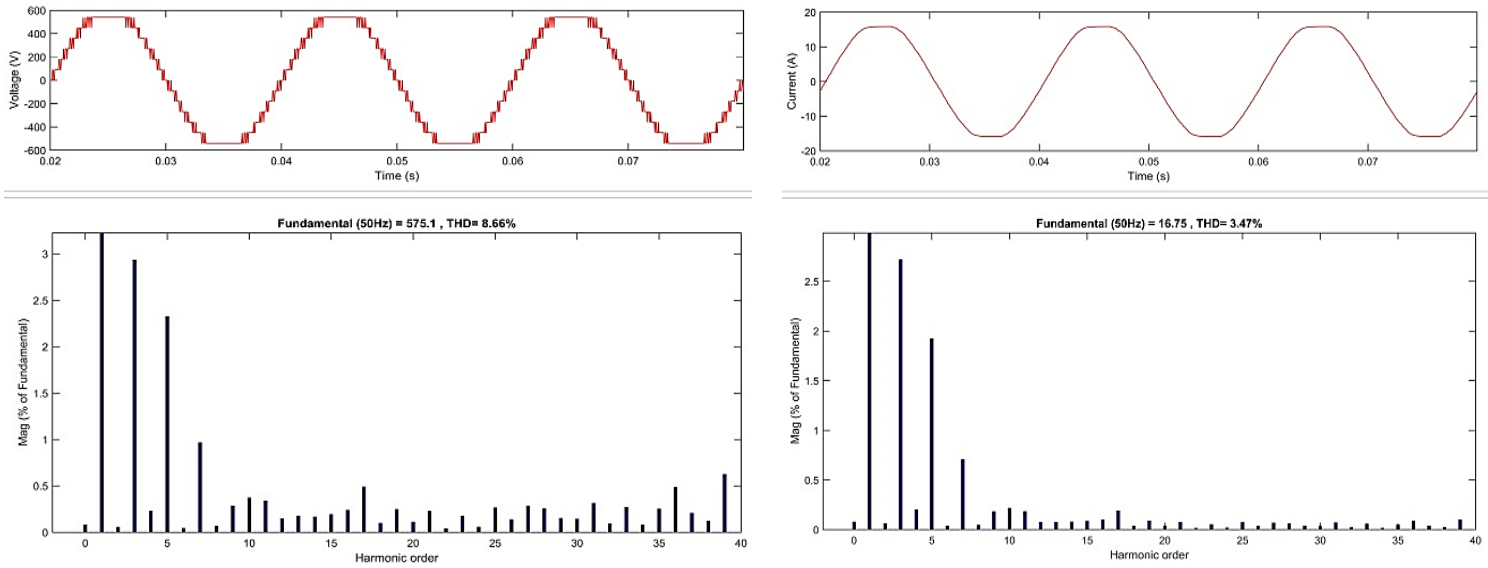

Figure 8. Voltage waveform and harmonic spectrum for static load-1

Figure 9. Current waveform and harmonic spectrum for static load-1
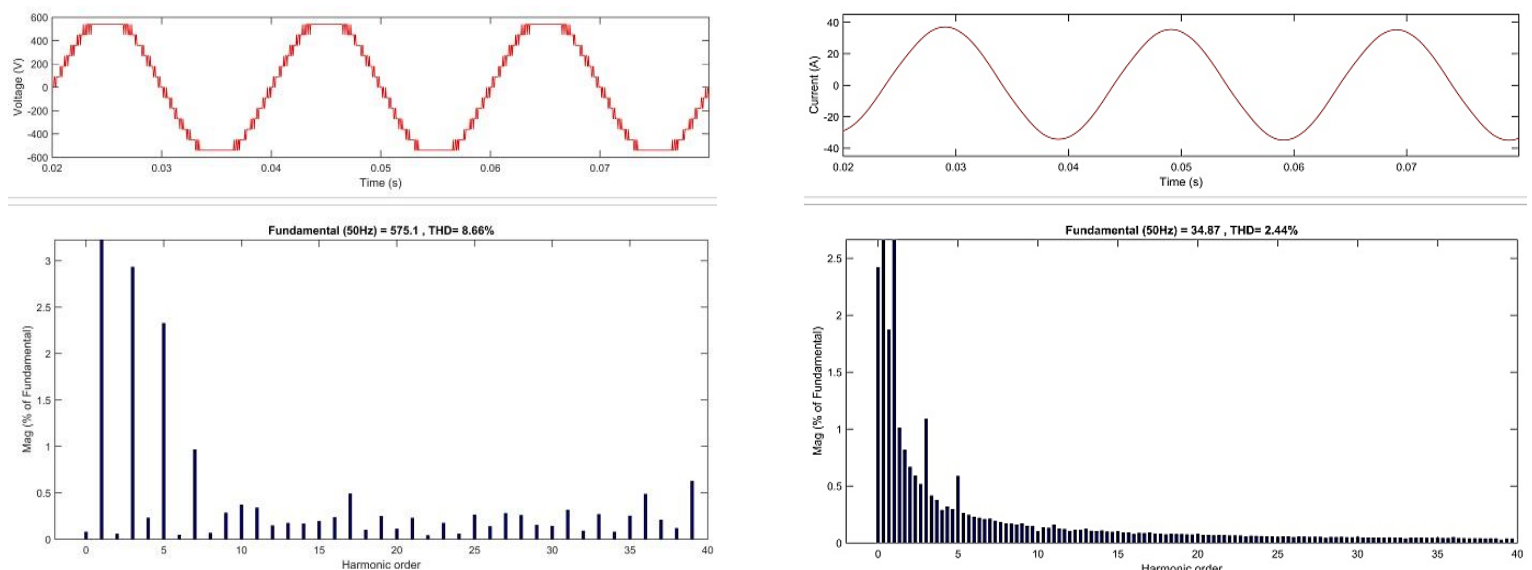

Figure 10. Voltage waveform and harmonic spectrum for static load-2

Figure 11. Current waveform and harmonic spectrum for static load-2 
For the third case study, dynamic load (induction motor IM) is connected to the proposed MLI. Figures 12 and 13 show the output phase voltage and current waveforms associated with harmonic spectrum and THD value. The results show that dynamic load forms higher current THD than static loads (resistive and inductive). This is due to the asymmetric distribution of magneto-motive force (MMF) which forms additional harmonic currents, as a result of the winding distribution in induction motor stator slots [25].
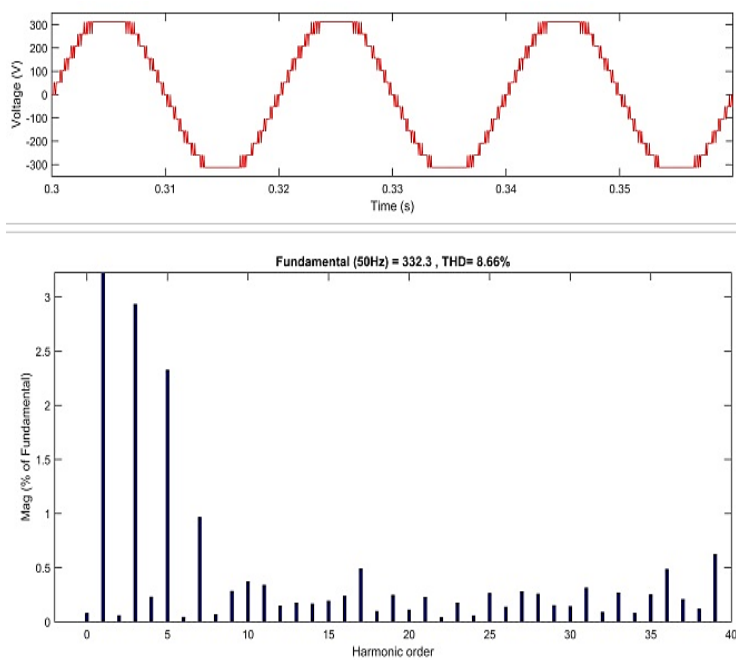

Figure 12. Voltage waveform and harmonic spectrum for dynamic load
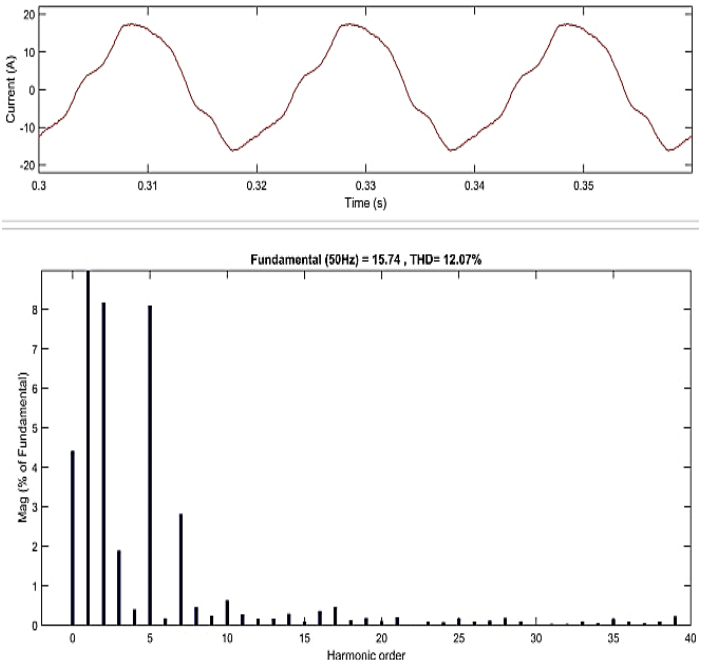

Figure 13. Current waveform and harmonic spectrum for dynamic load

Simulation results show that the modified MLI configuration (Thirteen-level inverter) with the improved modulation methodology (H-PWM) succeed to achieve highly accepted results by providing much more reduced THD if compared with other MLI configurations and modulation techniques. When the modified technique (H-PWM) is applied on the proposed MLI topology, voltage THD decreases to be $8.66 \%$ instead of $10.03 \%$. All of these performance improvements are achieved by adjusting the modulation technique and re-constructing the configuration of a recent MLI. These results are summarized in Table 5. As well, all simulations are performed without using any harmonics filter. In case a certain application requires reducing the waveform THD, a small filter will be required without affecting the size or the overall cost of the proposed MLI topology.

Table 5. Comparison between recent and modified MLI topologies

\begin{tabular}{cccccc}
\hline Topology & No. of Sources & No. of Switches & No. of Levels & Modulation Method & Voltage THD \\
\hline Recent Topology & 3 & 8 & 11 & PS-PWM & $12.48 \%$ \\
Modified Topology & 3 & 8 & 13 & H-PWM & $8.66 \%$ \\
\hline
\end{tabular}

The fourth case study is dedicated to control an induction motor through DTC drive while using the proposed thirteen-level MLI. MATLAB/Simulink simulation model applies MLI which offers 126 non-zero voltage vectors. Hence, DTC drive is more adaptable to reduce the torque and flux ripples through selecting the most fitting voltage vector for any operating condition. Consequently, the simulation results show enhanced performance of DTC drive. Figure 14 shows the torque and speed waveforms at load variation condition. Where the load changes from zero to 25 N.m and the speed is kept at $1430 \mathrm{rpm}$.

Figure 15 shows the torque and speed waveforms at speed reversal condition; speed changes from 1430 to- $1430 \mathrm{rpm}$ while keeping torque at $25 \mathrm{~N} . \mathrm{m}$. These waveforms indicate that torque ripples are around $8 \%$ of the rated torque. At the moments of motor starting or speed reversal, there is a momentary torque overshoot to overcome the motor and load inertia. This torque overshoot lasts for an accepted time period; less than $0.1 \mathrm{sec}$.

Figure 16 presents the stator flux locus (trajectory), where the flux ripples are nearly negligible. This low flux ripples helps to reduce the motor acoustic noise and harmonics. DTC drive succeeds to preserve the commanded torque and flux within the required hysteresis band widths. Figure 17 shows the stator voltage and current waveforms which are smooth waveforms with low harmonics content. The results show clearly 
the improvement of DTC drive performance after using the modified MLI. This is due to the application of thirteen-level MLI which has plentiful voltage vectors for different operating conditions, this reflects into limited torque and flux ripples. Additionally, the response of DTC drive is speedy, where the induction motor needs less than $0.1 \mathrm{sec}$ to reach the steady-state condition.
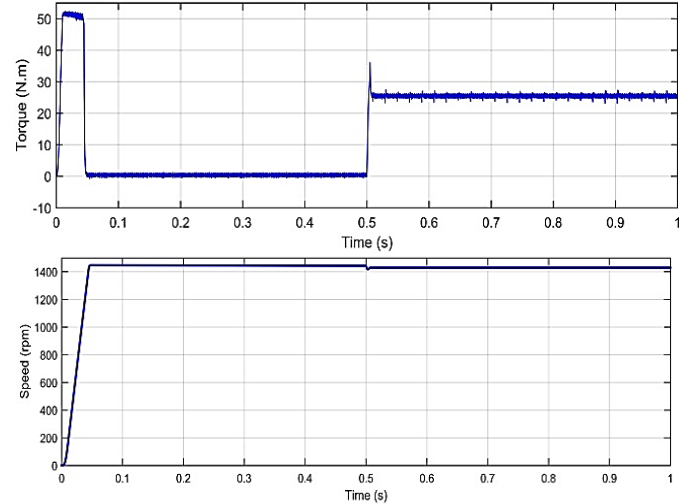

Figure 14. Torque and speed response at load variation condition ( 0 N.m, 25 N.m at $1430 \mathrm{rpm})$
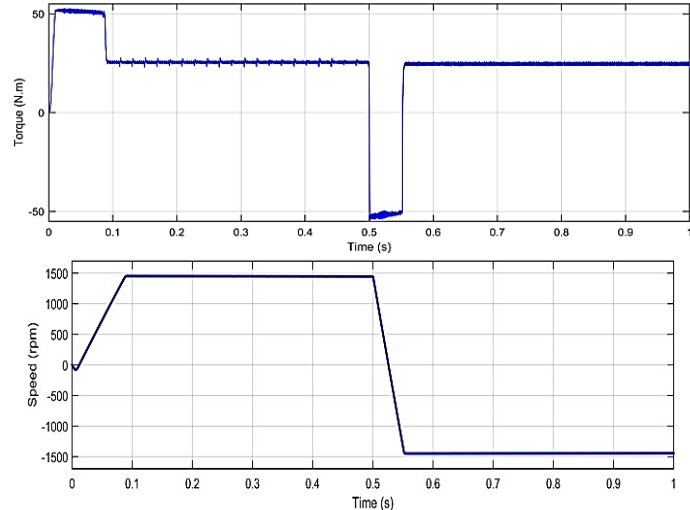

Figure 15. Torque and speed response at speed reversal condition (1430 rpm, -1430 rpm at 25 N.m)

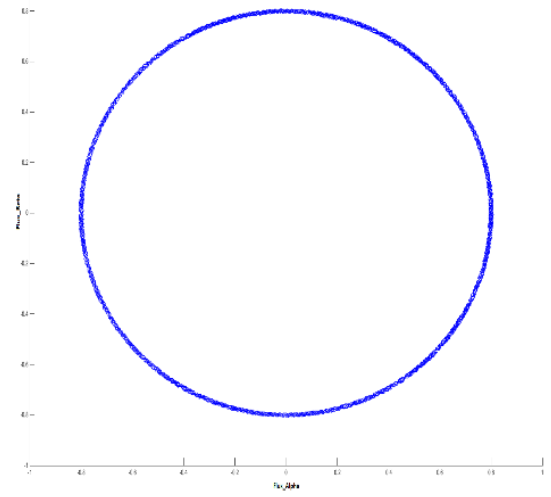

Figure 16. Flux trajectory $(0.8 \mathrm{wb})$

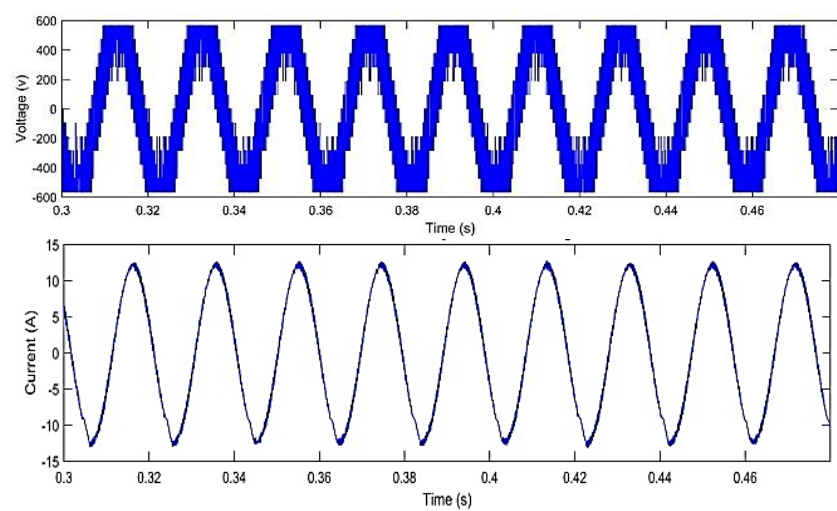

Figure 17. Voltage and current waveforms (25 N.m, 1430 rpm)

\section{CONCLUSION}

This paper presents a modified modulation technique to control the operation of MLI switches. When this modified method (H-PWM) is evaluated through various case studies and compared with other 
methodologies, H-PWM methodology reduces the voltage THD significantly from $12.48 \%$ to $10.03 \%$. In addition, this paper re-constructs a recently proposed MLI topology to produce higher number of voltage levels using the same components. This modified configuration uses only three DC sources and eight uni-directional switches to produce thirteen voltage levels. This high number of voltage levels in combination with the modified modulation methodology (H-PWM) helps to reduce the voltage THD from $10.03 \%$ to $8.66 \%$. The modified modulation methodology and MLI configuration succeed to offer multiple advantages like: simpler switches control, more circuit compactness, and lower THD without using any harmonics filter. Correspondingly, the paper introduces an application for the proposed MLI by being utilized with a DTC induction motor drive. This drive has an enhanced response at several operating conditions where the drive is characterized to be of reduced torque and flux ripples, and stable dynamic response.

\section{REFERENCES}

[1] M. M. Renge and H. M. Suryawanshi, "Five-Level Diode Clamped Inverter to Eliminate Common Mode Voltage and Reduce \$dv/dt\$ in Medium Voltage Rating Induction Motor Drives," IEEE Transactions on Power Electronics, vol. 23, no. 4, pp. 15981607, July 2008, doi: 10.1109/TPEL.2008.925423.

[2] P. Kant and B. Singh, "A Sensorless DTC Scheme for 60-Pulse AC-DC Converter Fed 5-Level Six-Leg NPC Inverter Based Medium Voltage Induction Motor Drive,” IEEE Transactions on Energy Conversion, vol. 35, no. 4, pp. 1916-1925, Dec. 2020, doi: 10.1109/TEC.2020.2997240.

[3] P. Sotoodeh and R. D. Miller, “A New Multi-level Inverter with FACTS Capabilities for Wind Applications,” 2013 IEEE Green Technologies Conference (GreenTech), 2013, pp. 271-276, doi: 10.1109/GreenTech.2013.49.

[4] R. K. Antar, B. M. Saied and R. A. Khalil, "Using seven-level cascade H-bridge inverter with HVDC system to improve power quality," 2012 First National Conference for Engineering Sciences (FNCES 2012), 2012, pp. 1-7, doi: 10.1109/NCES.2012.6740457.

[5] M. Almelian et al., "Enhancement of cascaded multi-level VSC STATCOM performance using ANN in the presence of faults," International Journal of Power Electronics and Drive System (IJPEDS), vol. 11, no. 2, pp. 895-906, 2020, doi: 10.11591/ijpeds.v11.i2.pp895-906.

[6] B. Aziza and A. Rufer, "A high voltage direct current transmission system: natural and selective harmonic cancellation," International Journal of Power Electronics and Drive System (IJPEDS), vol. 10, no. 3, pp. 1410-1418, 2019, doi: 10.11591/ijpeds.v10.i3.pp1410-1418.

[7] Krishna R and L. P. Suresh, "A brief review on multi level inverter topologies," 2016 International Conference on Circuit, Power and Computing Technologies (ICCPCT), 2016, pp. 1-6, doi: 10.1109/ICCPCT.2016.7530373.

[8] R. Mali, N. Adam, A. Satpaise and A. P. Vaidya, "Performance Comparison of Two Level Inverter with Classical Multilevel Inverter Topologies," 2019 IEEE International Conference on Electrical, Computer and Communication Technologies (ICECCT), 2019, pp. 1-7, doi: 10.1109/ICECCT.2019.8869115.

[9] T. Ahmadzadeh, M. Sabahi and E. Babaei, "Modified PWM control method for neutral point clamped multilevel inverters," 2017 14th International Conference on Electrical Engineering/Electronics, Computer, Telecommunications and Information Technology (ECTI-CON), 2017, pp. 765-768, doi: 10.1109/ECTICon.2017.8096351

[10] P. Mehta and M. Kumar, "Capacitor voltage balancing and THD analysis in ANPC multilevel inverter," 2018 IEEMA Engineer Infinite Conference (eTechNxT), 2018, pp. 1-5, doi: 10.1109/ETECHNXT.2018.8385376.

[11] M. M. Shobini, J. Kamala and R. Rathna, "Analysis and simulation of flying capacitor multilevel inverter using PDPWM strategy," 2017 International Conference on Innovative Mechanisms for Industry Applications (ICIMIA), 2017, pp. 91-95, doi: 10.1109/ICIMIA.2017.7975578.

[12] K. Sadigh, V. Dargahi, M. Abarzadeh and S. Dargahi, "Reduced DC voltage source flying capacitor multicell multilevel inverter: analysis and implementation," IET Power Electronics, vol. 7, no. 2, pp. 439-450, 2014, doi: 10.1049/iet-pel.2013.0071.

[13] H. Kumar and M. M. Lokhande, "Analysis of PWM techniques on multilevel cascaded H-Bridge three phase inverter," 2017 Recent Developments in Control, Automation \& Power Engineering (RDCAPE), 2017, pp. 465-470, doi: 10.1109/RDCAPE.2017.8358316.

[14] Prayag and S. Bodkhe, "A comparative analysis of classical three phase multilevel (five level) inverter topologies," 2016 IEEE 1st International Conference on Power Electronics, Intelligent Control and Energy Systems (ICPEICES), 2016, pp. 1-5, doi: 10.1109/ICPEICES.2016.7853567.

[15] G. V. V. Nagaraju and G. Sambasiva Rao, "Three-phase five-level CHB inverter fed induction motor for renewable applications," International Journal of Power Electronics and Drive System (IJPEDS), vol. 11, no. 3, pp. 1145-1152, 2020, doi: 10.11591/ijpeds.v11.i3.pp1145-1152.

[16] T. Porselvi and R. Muthu, "Comparison of Cascaded H-Bridge, Neutral Point Clamped and Flying Capacitor multilevel inverters using multicarrier PWM,” 2011 Annual IEEE India Conference, 2011, pp. 1-4, doi: 10.1109/INDCON.2011.6139534.

[17] M. D. Siddique, S. Mekhilef, N. M. Shah, A. Sarwar, A. Iqbal and M. A. Memon, "A New Multilevel Inverter Topology With Reduce Switch Count," in IEEE Access, vol. 7, pp. 58584-58594, 2019, doi: 10.1109/ACCESS.2019.2914430.

[18] K. K. Gupta, A. Ranjan, P. Bhatnagar, L. K. Sahu and S. Jain, "Multilevel Inverter Topologies With Reduced Device Count: A Review," in IEEE Transactions on Power Electronics, vol. 31, no. 1, pp. 135-151, Jan. 2016, doi: 10.1109/TPEL.2015.2405012.

[19] H. Hashim and I. Abdel-Qader, “A new reduced-switch-count cascaded multicell converter," 2017 IEEE International Conference on Electro Information Technology (EIT), 2017, pp. 525-529, doi: 10.1109/EIT.2017.8053418.

[20] Takahashi and T. Noguchi, "A New Quick-Response and High-Efficiency Control Strategy of an Induction Motor," in IEEE Transactions on Industry Applications, vol. IA-22, no. 5, pp. 820-827, Sept. 1986, doi: 10.1109/TIA.1986.4504799.

[21] V. Goutham, T. Himabindu, V. Vikas and G. B. B. Singh, "Performance improvement using a multi-level converter in a DTC based induction motor drive," 2015 IEEE IAS Joint Industrial and Commercial Power Systems / Petroleum and Chemical Industry Conference (ICPSPCIC), 2015, pp. 52-59, doi: 10.1109/CICPS.2015.7974053.

[22] M. F. Escalante, J. -. Vannier and A. Arzande, "Flying capacitor multilevel inverters and DTC motor drive applications," in IEEE Transactions on Industrial Electronics, vol. 49, no. 4, pp. 809-815, Aug. 2002, doi: 10.1109/TIE.2002.801231. 
[23] P. McGrath and D. G. Holmes, "Multicarrier PWM strategies for multilevel inverters," in IEEE Transactions on Industrial Electronics, vol. 49, no. 4, pp. 858-867, Aug. 2002, doi: 10.1109/TIE.2002.801073.

[24] Rodriguez, J. Pontt, S. Kouro and P. Correa, "Direct torque control with imposed switching frequency and torque ripple minimization in an 11-level cascaded inverter," IEEE 34th Annual Conference on Power Electronics Specialist, 2003. PESC '03., 2003, pp. 501-506 vol.2, doi: 10.1109/PESC.2003.1218106.

[25] H. Asgharpour-Alamdari, Y. Alinejad-Beromi and H. Yaghobi, "Improvement of induction motor operation using a new winding scheme for reduction of the magnetomotive force distortion," IET Electric Power Applications, vol. 12, no. 3, pp. 323-331, 2018, doi: 10.1049/iet-epa.2017.0381.

\section{BIOGRAPHIES OF AUTHORS}
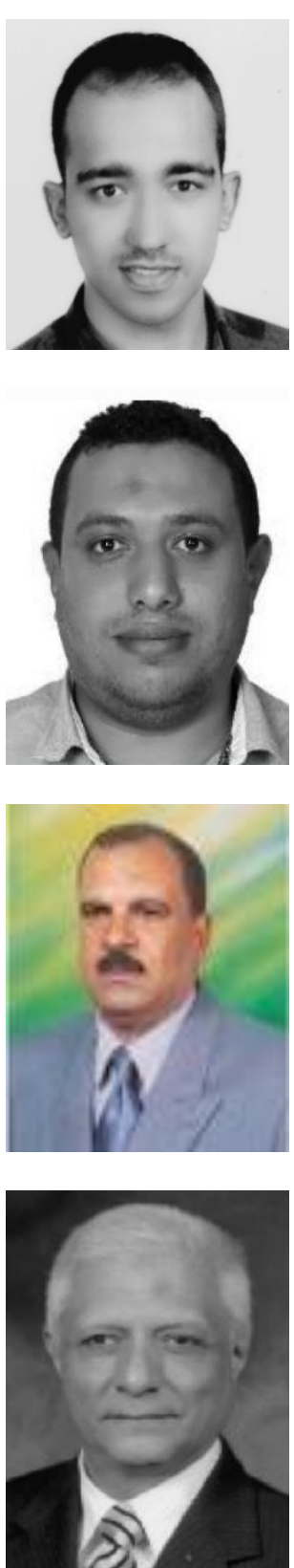

Mahmoud Samy (iD IS SC P received the B.Sc. (Hons.) degree from Ain Shams University, Cairo, Egypt, in 2017. He is currently pursuing the M.Sc. degree at Ain Shams University, Cairo, Egypt. Currently, he is a teaching assistant at the Department of Electrical Power and Machines, Ain Shams University since 2017. His research interests include the areas of modeling and control of power electronics converters, renewable energy systems, and induction motor drives. He can be contacted at email: mahmoudsamy93@eng.asu.edu.eg.

Mohamed Mokhtar (iD 8 SC P received the B.Sc. (Hons.), M.Sc. and Ph.D. degrees from Ain Shams University, Cairo, Egypt, in 2010, 2014 and 2018, respectively. Currently, he is a teacher at the Department of Electrical Power and Machines, Ain Shams University since 2018. His research interests include the areas of modeling and control of power electronics converters, renewable generation, and dc microgrids. He can be contacted at email: m.mokhtar@eng.asu.edu.eg.

Naggar Hassan Saad (D) SC P received the B.Sc. (Hons.), M.Sc. and Ph.D. degrees from Ain Shams University, Cairo, Egypt, in 1987, 1994 and 2003, respectively. Currently, he is a professor at the Department of Electrical Power and Machines, Ain Shams University since 2017. His research interests include power electronics, control of electrical machines, FACTs, and renewable energy systems. $\mathrm{He}$ can be contacted at email: naggar_hemdan@eng.asu.edu.eg.

Ahmed Abd El-Sattar (D) SC S P received the B.Sc. degree from Cairo University, Cairo, Egypt, in 1967, M.Sc. degree from Ain Shams University, Cairo, Egypt, in 1969, and the Ph.D. degree from the Academy of Science, Budapest, Hungary, in 1975, all in electrical engineering. He was the head of the electrical power and machines department, Faculty of Engineering, Ain Shams University during 2005/2006. Currently, he is a professor at the Department of Electrical Power and Machines, Ain Shams University. His research interests include power electronics, control of electrical machines, and renewable energy systems. He can be contacted at email: ahmed_abdelfattah@eng.asu.edu.eg. 